\title{
Shear wave elasticity by tracing total nodule showed high reproducibility and concordance with fibrosis in thyroid cancer
}

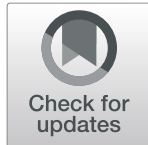

Myung Hi Yoo ${ }^{1,2^{*}+}$, Hye Jeong Kim', In Ho Choi ${ }^{3}$, Suyeon Park', Sang Jin Kim, Hyeong Kyu Park', Dong Won Byun ${ }^{1}$ and Kyoil Suh ${ }^{1}$

\begin{abstract}
Background: Although shear wave elastography (SWE) is reported to be useful in detecting malignant thyroid nodules, it shows a wide range of cut-off values of elasticity index (EI) in detecting malignant nodules. The cause of discrepancy remains unclear. Fibrosis of the tumors is known to increase the El in SWE, and matching of SWE and surgical histopathology has not been fully illustrated in thyroid cancer. We aimed to evaluate the reproducibility of the new total nodular region of interest (ROI) method excluding the subjective features of focal circular ROI placement and to determine the lesion that causes the elevation of EI on SWE and on histopathology.
\end{abstract}

Methods: A total of 29 thyroid cancers from 28 patients were included. We evaluated the reproducibility of $\mathrm{El}$ in the new total nodular $\mathrm{ROI}$ using Q-Box Trace program and compared the $\mathrm{El}$ in focal nodular $\mathrm{ROI}$ using a 3-mm circular area. We analyzed the correlation between fibrosis and El.

Result: The coefficient of variation (CV) of the intrarater assay was significantly lower in total nodular ROI than in focal nodular $\mathrm{ROI}$ within the image in rater $1(1.7 \%$ vs. $13.4 \%, p<0.001)$ and in rater $2(1.4 \%$ vs. $16.9 \%, p<0.001)$ and in different images in rater 1 ( $7.6 \%$ vs. $12.3 \%, p=0.040)$ and in rater $2(7.5 \%$ vs. 19.8\%, $p=0.004)$. Moreover, CV of the interrater assay showed similar results (14.9\% vs. $19 \%, p=0.030)$. Interrater intraclass correlation coefficient showed better agreement in total nodular ROI than in focal nodular ROI (0.863 vs. 0.783). The degree of fibrosis on histopathology showed significant correlations with $\mathrm{El}\left(\mathrm{E}_{\mathrm{Mean}}, p<0.001 ; \mathrm{E}_{\mathrm{Max}}, p=0.027\right)$, and the location of fibrosis was concordant with the high El area on SWE.

Conclusion: Our study revealed that the new total nodular ROI method showed higher reproducibility and better agreement in intra- and interrater assay than the focal nodular ROI method, suggesting a valuable and standardized method in clinical practice. Moreover, our results showed that fibrosis in the histopathology increased El on SWE and might lead to the discrepancy of the cut-off values in detecting thyroid cancer.

Keywords: Elastography, Shear wave, Thyroid cancer, Fibrosis

\footnotetext{
*Correspondence: mhyoo@schmc.ac.kr; elimyoo11@gmail.com

${ }^{\dagger}$ Myung $\mathrm{Hi}$ Yoo and Hye Jeong Kim contributed equally to this work.

${ }^{1}$ Division of Endocrinology and Metabolism, Department of Internal

Medicine, Soonchunhyang University Hospital, Soonchunhyang University

College of Medicine, 59 Daesagwan-ro, Yongsan-gu, Seoul 140-743, Republic

of Korea

${ }^{2}$ Elim Thyroid Clinic, Seoul, South Korea

Full list of author information is available at the end of the article
}

(c) The Author(s). 2020 Open Access This article is distributed under the terms of the Creative Commons Attribution 4.0 International License (http://creativecommons.org/licenses/by/4.0/), which permits unrestricted use, distribution, and reproduction in any medium, provided you give appropriate credit to the original author(s) and the source, provide a link to the Creative Commons license, and indicate if changes were made. The Creative Commons Public Domain Dedication waiver (http://creativecommons.org/publicdomain/zero/1.0/) applies to the data made available in this article, unless otherwise stated. 


\section{Background}

A thyroid nodule is a common finding in up to $60 \%$ of the population during ultrasound (US) examination, and the malignancy rate for the thyroid nodules is $5-15 \%$ [1, 2]. Fine-needle aspiration (FNA) cytology is the first step that is performed to differentiate malignant nodules; however, 5-15\% of FNA revealed inadequate nondiagnostic samples, and 15-30\% of FNA result in indeterminate cytologic findings category III (atypia or follicular neoplasm of undetermined significance) and category IV (suspicious for follicular neoplasm) according to the Bethesda system [3, 4]. Hence, additional tools to aid in the differentiation of malignant nodules are needed.

US elastography had been reported to be useful in the differentiation of benign and malignant thyroid nodules [5-9]. Strain elastography was initially developed with the operator using manual compression on the tissue to measure tissue displacement (strain) caused by the compression (stress) [10]. However, strain elastography had several disadvantages including high operator dependence in terms of compression and absence of sufficient quantitative information $[11,12]$. Shear wave elastography (SWE) uses several focused ultrasonic pushing beams to generate shear waves and measures transversely propagated shear wave speed, and the subsequent ultrafast echographic imaging sequence generates a quantitative elastogram [13]. SWE has sufficient quantitative information and is operator independent in terms of compression; hence, it is expected to result in more reproducible findings than strain elastography, and two-dimensional SWE (2D-SWE) represents focal tissue stiffness map [14, 15]. Studies using SWE to assess the thyroid nodules have reported its usefulness in detecting malignant nodules. However, there was a wide range of cut-off values of elasticity index (EI) in detecting malignant nodules ranging from $34 \mathrm{kPa}$ to 90 $\mathrm{kPa}[9,16-25]$. Thyroid nodules usually show heterogeneous images of EI within the nodule on 2D-SWE; thus, selecting different locations of region of interest (ROI) within the nodule displays different ROI even with the same operator $[12,26]$. Difficulty in imaging and the subjective features of selecting representative location of ROI in thyroid nodules with heterogeneous EI contribute to variable EI profiles in SWE [27, 28]. Therefore, SWE is not operator dependent in terms of the added stress (compression) but operator dependent in the placement of ROI. To decrease this subjective variance in the placement of ROI in thyroid nodules, we let the total nodular area the ROI by tracing the total nodular margin using the overlapping B-mode US. To the best of our knowledge, this is the first trial to evaluate the total area of the nodule by tracing the nodular margin. We compared the reproducibility and reliability of EI between the total nodular ROI and the focal nodular ROI using 3-mm circular area.
Tissue elasticity is known to increase more in fibrosis [14] than in solid tumor formation [29]. Additionally, it has been reported that elasticity on strain elastography and SWE is increased relative to fibrosis but not with cellularity in the papillary thyroid carcinoma (PTC) [3033]. We attempted to determine the pathological findings matching the high EI areas in 2D-SWE by comparing 2D-SWE of the thyroid nodule with surgical histopathology.

First, we aimed to investigate the reliability and reproducibility of EI by SWE in the new total nodular ROI and to compare it with EI in the focal nodular ROI to validate the adequacy of EI by SWE as a reliable parameter of stiffness. Second, we examined the relationship between the degree and location of fibrosis in the surgical histopathology and the magnitude and location of high EI area on 2D-SWE.

\section{Methods \\ Study population}

Data of 588 patients who visited the thyroid clinic of the Soonchunhyang University Hospital for the evaluation of thyroid nodules and who underwent SWE before US guided FNA or core-needle biopsy from November 2015 to May 2018 were retrospectively reviewed for inclusion in this study.

Among these subjects, 44 were found to have thyroid cancer on surgical pathology. Patients with poor results in SWE including, thyroid nodules with poor shear wave mapping $(n=7)$ or with macrocalcifications $(n=3)$ and presence of nodules at the isthmic/paraisthmic areas due to the interference produced by the tracheal cartilage $(n=5)$ were excluded. Finally, data from 29 thyroid cancers in 28 patients were included in this study. There were 24 cases of conventional type of PTC, 2 cases of follicular variant PTC, 2 cases of follicular thyroid carcinoma and 1 case of medullary thyroid carcinoma.

\section{Gray-scale ultrasound and shear wave elastography examinations}

The patients were positioned for US with their necks extended. Each patient underwent gray-scale US and SWE using the Aixplorer US system (SuperSonic Imagine, Aixen-Provence, France) and a linear probe with a frequency range of $15-4 \mathrm{MHz}$. During gray-scale US examination, thyroid nodules were evaluated for size (width, depth and length), volume, composition, orientation, echogenicity, shape, margin, and presence or absence of calcification.

After the gray-scale US, SWE was performed by the same operator who had performed the gray-scale US using the same probe. To avoid compression artifacts, generous amount of gel was used. The probe was held static in the transverse plane at the center of the nodule until the image had stabilized. After two or three cine- 
loop images were acquired, one representative elastogram with the fewest artifacts in each cine-loop image was selected.

Total nodular ROI was determined by drawing the margin of the nodule guided by the overlaid B-mode anatomic scan with the mode of the machine setting using the Q-Box Trace program. We drew the margin of ROI avoiding the areas of macrocalcification and cystic portion. The EI of the total nodular ROI was calculated and displayed using the machine. The mean $\left(\mathrm{E}_{\text {Mean }}\right)$, minimum $\left(\mathrm{E}_{\mathrm{Min}}\right)$, maximum $\left(\mathrm{E}_{\mathrm{Max}}\right)$, and standard deviation $\left(E_{\mathrm{SD}}\right)$ of SWE EI values in the ROI were calculated as $\mathrm{kPa}$, and 2D-SWE was color coded from dark blue (less than $36 \mathrm{kPa}$ ), light blue (36-72 $\mathrm{kPa}$ ), green, yellow, to red (greater than $180 \mathrm{kPa}$ ). For the focal nodular ROI, the EI in 2-3 ROI using a 3$\mathrm{mm}$ circular area containing the stiffest area was measured. Moreover, the high EI area of the nodule where the color-coded EI showed higher EI than light blue (which is greater than $36 \mathrm{kPa}$ ) was traced by the manual drawing, and the area was calculated and displayed by the machine. The percentage of high EI area was calculated as high EI area divided by the total nodular area. For the evaluation of interrater agreement, the second physician performed the same examination immediately after the first physician.

\section{Pathological analysis}

Surgical specimen was cut in coronal section in the largest diameter corresponding to the center of the nodule on 2D-SWE. Surgical histopathology was stained with hematoxylin and eosin staining and was diagnosed according to the World Health Organization classification [34]. Collagen fibers on histological slides were stained with Masson's trichrome stain. Under low-power microscopy $(\times 12$ or $\times 40)$, the image of the area showing the thyroid carcinoma was taken. The area of fibrosis and the total area of the thyroid carcinoma under the low-power microscopy images were taken, and the areas were measured using the Q-Box Trace program calculating the area with the irregular margin, and the percentage of fibrotic area was calculated by dividing the fibrotic area by the total area of the tumor.

\section{Statistical analysis}

The tumor size and elasticity values of all the lesions were expressed as medians (25th, and 75th percentile). The differences between the thyroid carcinoma groups were compared using the Mann-Whitney U-test.

To assess the reproducibility of elasticity measurement, intra- and interrater agreements were evaluated using the intraclass correlation coefficient (ICC; two-way random, absolute agreement). Agreement for interrater measurements was also analyzed using Bland-Altman plots [35-37].
The coefficient of variation (CV) was calculated as the ratio of the standard deviation and mean value. A linear regression model was used to examine the correlation between EI and the percent of high EI area on SWE with the degree of fibrosis on histopathology. All statistical analyses were performed using the SPSS Statistics 25.0 software package (Chicago, IL, USA). $P$ values less than 0.05 were considered statistically significant.

\section{Results}

Intra- and Interrater agreement of mean elasticity in each method

One representative elastogram from each cine-loop of $2 \mathrm{im}$ ages was selected, and a total of 80 images from the 20 thyroid nodules from 18 subjects by two raters were obtained. The mean, SD, minimum, and maximum elasticity values of $\mathrm{E}_{\mathrm{Mean}}$, and intra- and interrater agreement for the quantitative measurements of $\mathrm{E}_{\mathrm{Mean}}$ are summarized in Table 1. For the total nodular ROI method, there was good intrarater agreement of $\mathrm{E}_{\text {Mean }}$ and ICC in rater 1 and rater 2 were 0.975 and 0.999 within the image and 0.959 and 0.976 in different images, respectively. The intrarater ICC of the focal nodular ROI method in rater 1 and rater 2 were 0.866 and 0.934 within the image and 0.734 and 0.894 in different images, respectively.

The first elastogram in each cine-loop was used to calculate the ICC and to assess the interrater agreement. Interrater ICC of the total nodular ROI and focal nodular ROI were 0.863 and 0.783 , respectively. The intrarater CVs of the total nodular ROI method in rater 1 and rater 2 were significantly lower than those of the focal nodular ROI method in rater 1 $(1.7 \%$ vs. $13.4 \%, p<0.001)$ and in rater $2(1.4 \%$ vs. $16.9 \%, p<0.001)$ within the image and in rater 1 (7.6\% vs. $12.3 \%, p=0.040)$ and in rater $2(7.5 \%$ vs. $19.8 \%, p=0.004)$ in different images. The interrater $\mathrm{CV}$ of the total nodular ROI method was significantly lower than the focal nodular ROI method $(14.9 \%$ vs. $19.0 \%, p=0.030)$. Analysis using the Bland-Altman plots for $E_{\text {Mean }}$ between the two raters is shown in Fig. 1. Bland-Altman analysis between the two raters for the total nodular ROI method showed a bias of 0.4 and limits of agreement of -12.9 to 13.7 , with a repeatability coefficient between the 2 raters of 13.3. The focal nodular ROI method showed a bias of -0.4 and limits of agreement of -16.4 to 15.6 , with a repeatability coefficient between the 2 raters of 16.0 .

\section{Correlation between elasticity index measurements on shear wave Elastography and the degree of fibrosis on surgical histopathology}

To evaluate the correlation between EI measurements on SWE and the degree of fibrosis on surgical histopathology, we reviewed and compared the SWE images and the 
Table 1 Shear wave elasticity values, and intra- and interrater intraclass correlation coefficient (ICC) agreement and coefficient of variation (CV) for $\mathrm{E}_{\text {Mean }}$ (mean elasticity) in region of interest (ROI) with the two methods (total nodular ROI with tracing total nodule and focal nodular $\mathrm{ROI}$ with $3 \mathrm{~mm}$ circle) by two raters

\begin{tabular}{|c|c|c|c|c|}
\hline \multirow[t]{2}{*}{ Method of ROI } & \multicolumn{2}{|c|}{$\mathrm{E}_{\text {Mean }}(\mathrm{kPa})$, mean $\pm \mathrm{SD}($ min-max $)$} & \multirow[t]{2}{*}{ ICC $(95 \% \mathrm{Cl})$} & \multirow{2}{*}{$\begin{array}{l}\text { CV } \\
(\%)\end{array}$} \\
\hline & Read 1 & Read 2 & & \\
\hline \multicolumn{5}{|l|}{ Total nodular ROI } \\
\hline \multicolumn{5}{|c|}{ Intrarater assay (within image) } \\
\hline Rater 1 & $25.3 \pm 10.0(12.0-49.6)$ & $24.7 \pm 9.0(12.1-40.1)$ & $0.975(0.983-0.990)$ & 1.7 \\
\hline Rater 2 & $24.3 \pm 11.7(9.6-58.7)$ & $24.3 \pm 11.9(9.2-59.9)$ & $0.999(0.997-1.000)$ & 1.4 \\
\hline \multicolumn{5}{|c|}{ Intrarater assay (different image) } \\
\hline Rater 1 & $24.8 \pm 9.0(12.0-40.0)$ & $24.6 \pm 9.4(9.3-41.7)$ & $0.959(0.895-0.984)$ & 7.6 \\
\hline Rater 2 & $24.3 \pm 11.7(9.6-58.7)$ & $26.0 \pm 13.1(10.3-60.8)$ & $0.976(0.933-0.991)$ & 7.5 \\
\hline Interrater assay & $25.3 \pm 10.0(12.0-49.6)$ & $24.3 \pm 11.7(9.6-58.7)$ & $0.863(0.653-0.946)$ & 14.9 \\
\hline \multicolumn{5}{|l|}{ Focal nodular ROI } \\
\hline \multicolumn{5}{|c|}{ Intrarater assay (within image) } \\
\hline Rater 1 & $34.0 \pm 17.2(14.4-86.3)$ & $39.6 \pm 22.9(16.3-115.2)$ & $0.934(0.842-0.973)$ & 13.4 \\
\hline Rater 2 & $45.0 \pm 36.8(12.4-179.9)$ & $36.6 \pm 23.4(10.4-111.8)$ & $0.866(0.693-0.945)$ & 16.9 \\
\hline \multicolumn{5}{|c|}{ Intrarater assay (different image) } \\
\hline Rater 1 & $34.0 \pm 17.2(14.4-86.3)$ & $33.6 \pm 11.9(11.2-53.7)$ & $0.894(0.730-0.958)$ & 12.3 \\
\hline Rater 2 & $45.0 \pm 36.8(12.4-179.9)$ & $37.1 \pm 19.1(11.1-93.1)$ & $0.734(0.347-0.894)$ & 19.8 \\
\hline Interrater assay & $34.0 \pm 17.2(14.4-86.3)$ & $45.0 \pm 36.8(12.4-179.9)$ & $0.783(0.443-0.915)$ & 19.0 \\
\hline
\end{tabular}

histological specimens for carefully selected group of patients as shown in Fig. 2. Our data suggested a strong positive correlation between high EI area on SWE and the degree of fibrosis on surgical histopathology $(r=0.847$, $p<0.001$ ) (Fig. 3a), and also between $\mathrm{E}_{\text {Mean }}$ and the degree of fibrosis on surgical histopathology $(r=0.706, p<0.001)$ (Fig. 3b). $\mathrm{E}_{\text {Max }}$ showed a weak positive correlation with the degree of fibrosis on surgical histopathology $(r=0.419$, $p=0.027$ ) (Fig. 3c). The fibrosis on surgical histopathology was higher in conventional PTCs (Group 1) than in the non-conventional PTCs including follicular variant PTCs, follicular thyroid carcinomas, and a medullary thyroid carcinoma (Group 2). Group 1 showed higher EI values and EI area than Group 2, which were statistically significant for $\mathrm{E}_{\text {Mean }}(p=0.012), \mathrm{E}_{\mathrm{Max}}(p=0.032), \mathrm{E}_{\mathrm{SD}}(p=0.016)$, and high EI area on SWE ( $p=0.003)$ (Fig. 4).

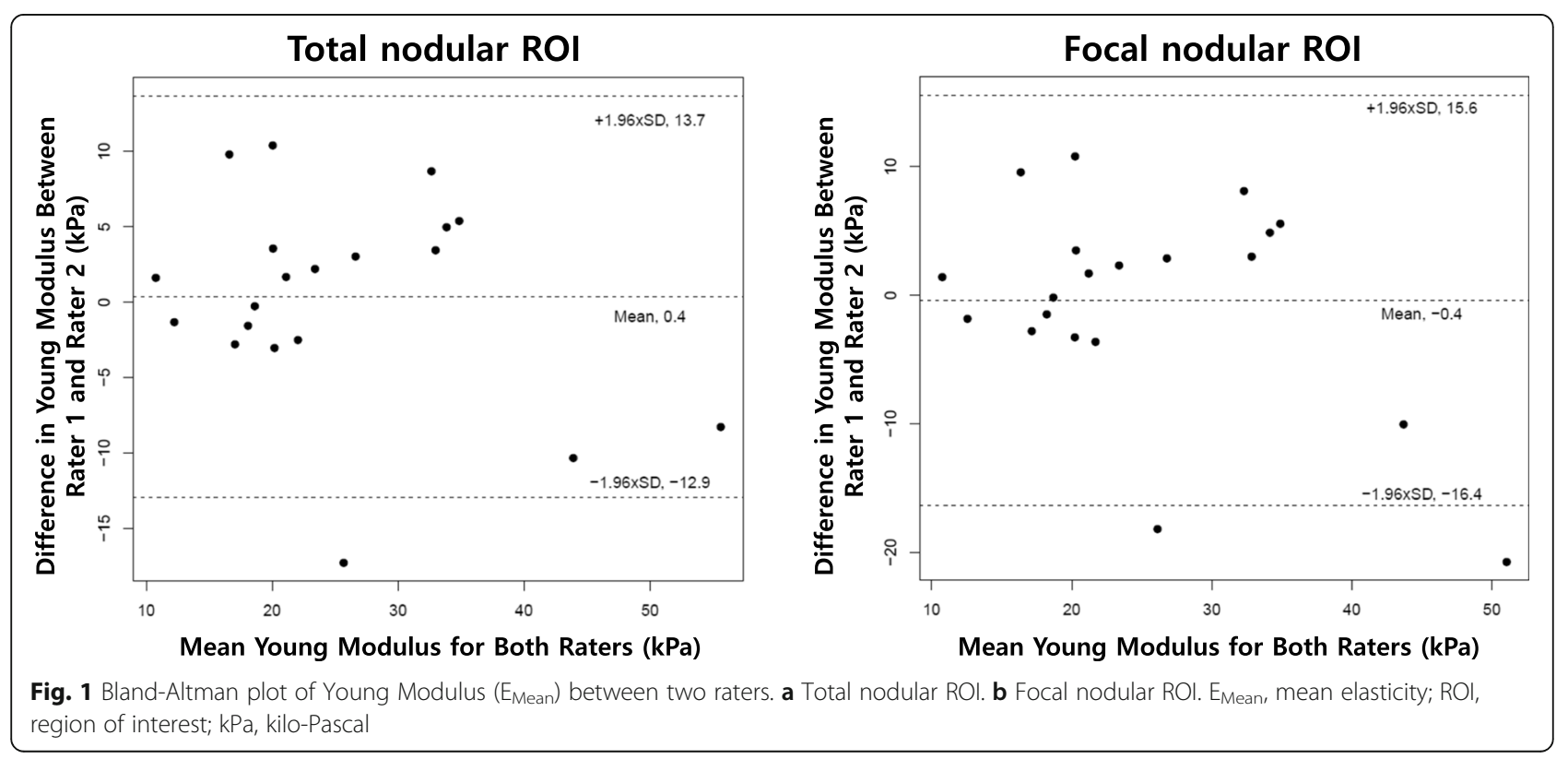



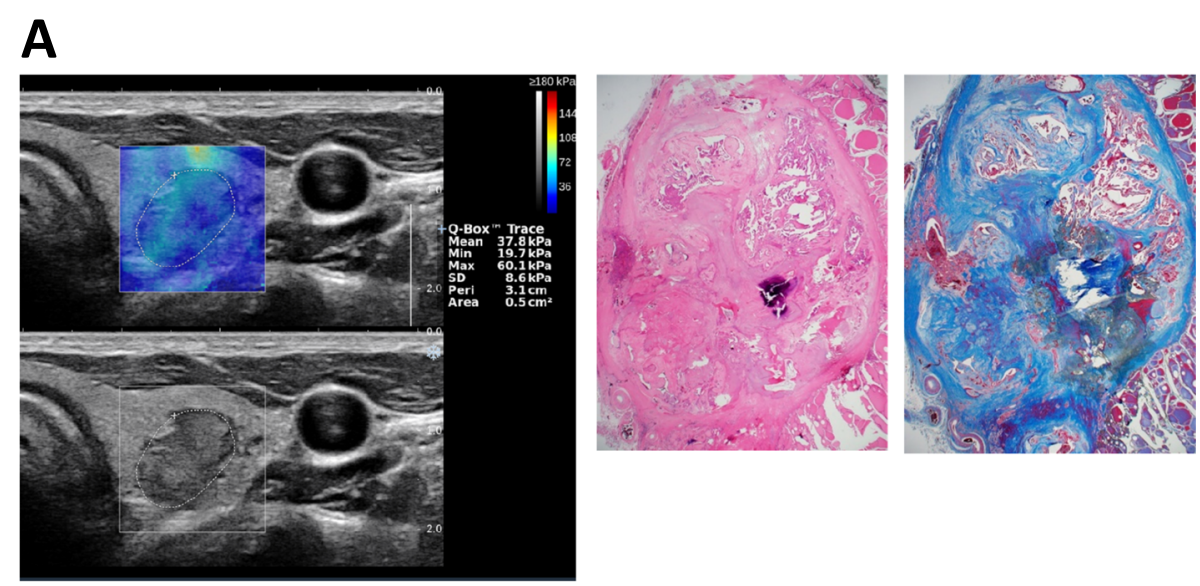

\section{B}
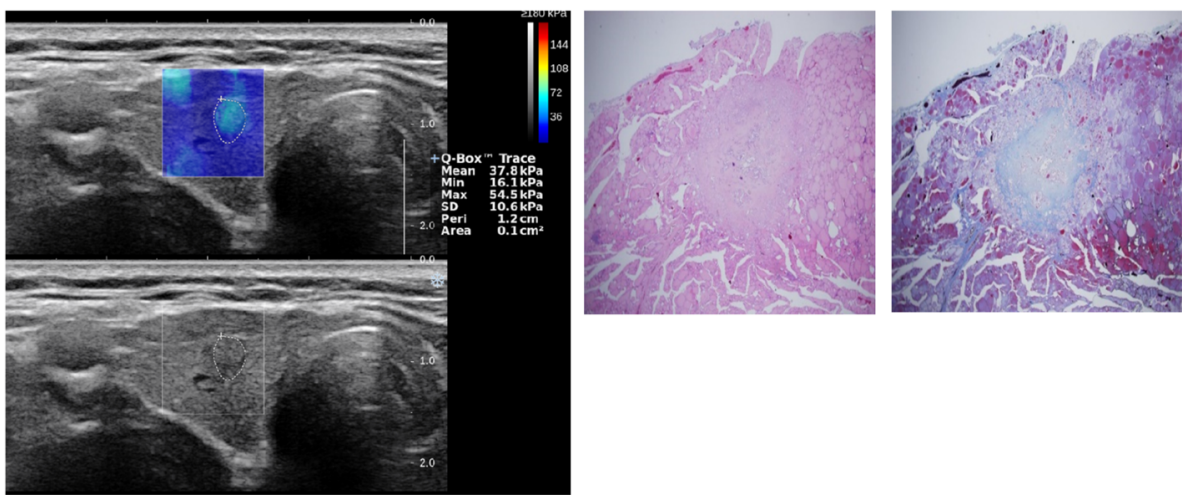

\section{C}
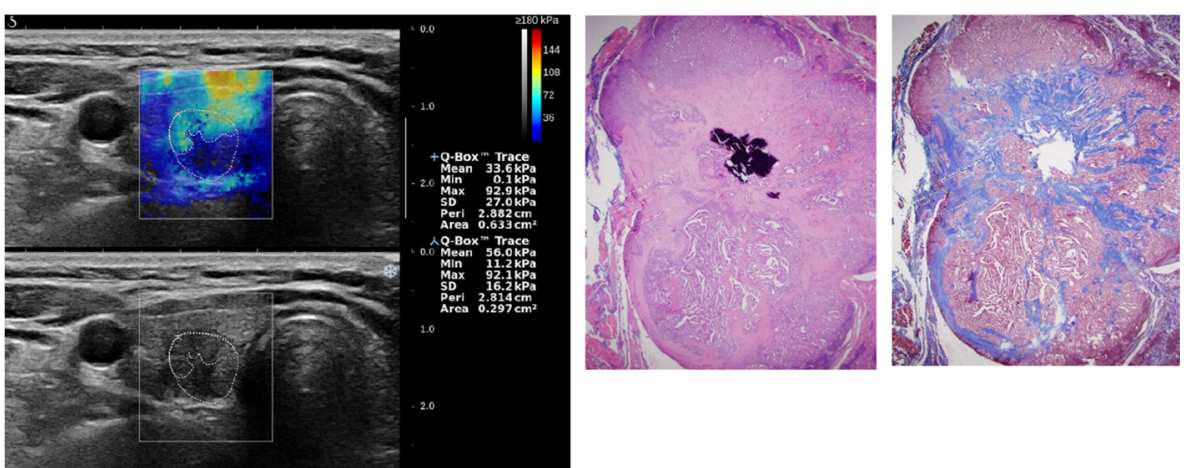

Fig. 2 Shear wave elastography (SWE), gray-scale ultrasound (US), H\&E staining, and Masson's trichrome staining slides of the papillary thyroid carcinoma in 3 patients. a The case is from a patient with a 1.63- $\mathrm{cm}$ left middle thyroid nodule. A suspicious malignant nodule with hypoechogenicity and lobulated margin was observed on gray-scale US. SWE showed generalized uneven distribution of high elasticity index (El) area within the nodule. Masson's trichrome staining showed uneven irregular distribution of fibrosis within the nodule, concordant with the high El area on SWE. $\mathbf{b}$ The case is from a patient with a $0.52-\mathrm{cm}$ right middle thyroid nodule. A suspicious malignant nodule with taller-than-wide shape, microcalcification, and irregular margin was observed on gray-scale US. SWE showed high El area over the entire nodule. On Masson Trichrome staining, fibrosis was observed in the entire nodule, concordant with the high El area on SWE. c The case is from a patient with a 1.00$\mathrm{cm}$ right lower thyroid nodule. A suspicious malignant nodule with hypoechogenicity, microcalcification, and lobulated margin was observed on gray-scale US. SWE showed high El area in the upper portion of the nodule. Similar to the high El area on SWE, fibrosis was observed in the upper portion of the nodule on Masson's trichrome staining 

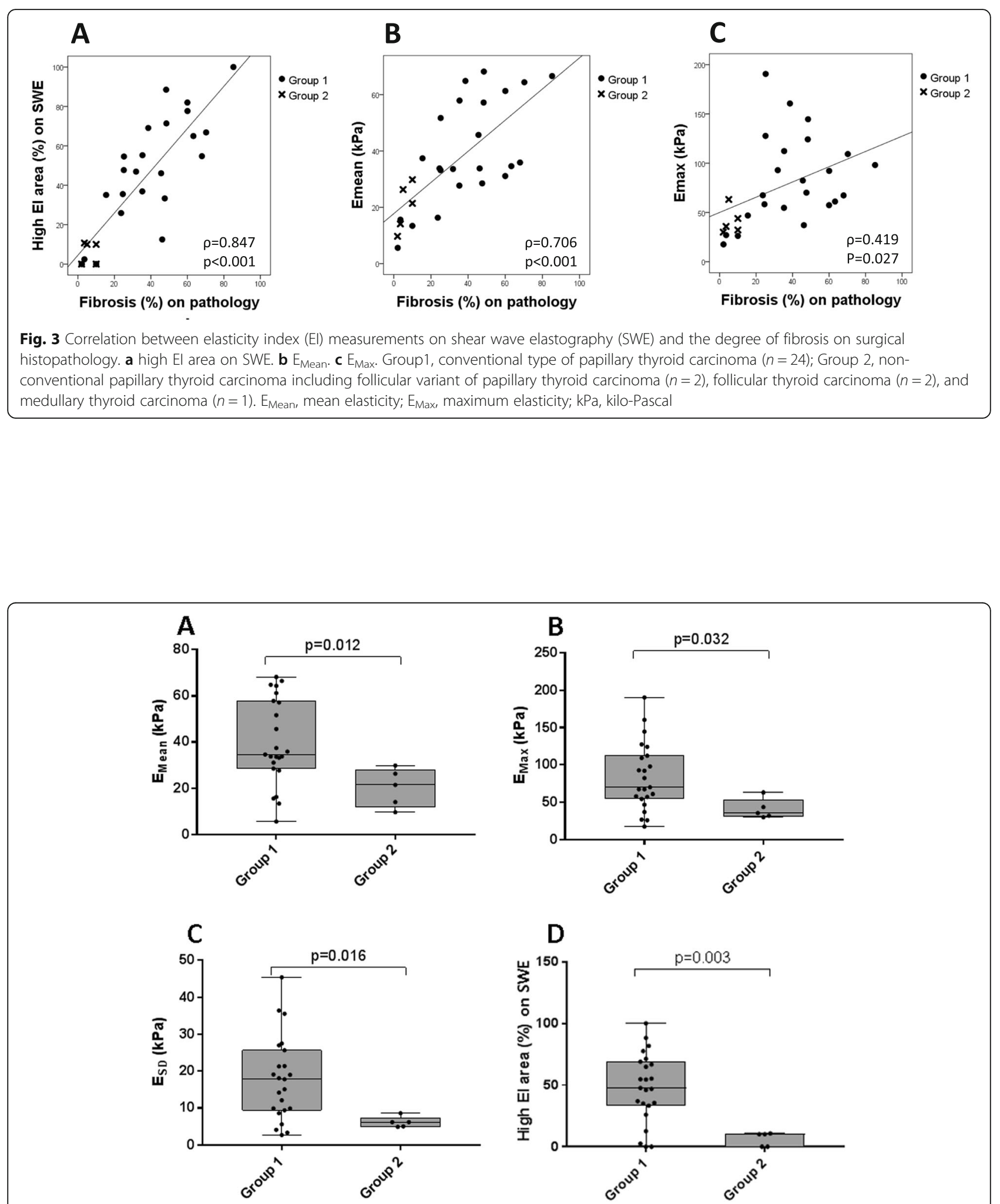

Fig. 4 Box-and-whisker plots of elasticity index (EI) measurements on shear wave elstography (SWE) for group 1 and group 2. a $E_{\text {Mean. }} \mathbf{b}$ $E_{\text {Max }} \cdot \mathbf{c} E_{S D}$. d high El area on SWE. Group1, conventional type of papillary thyroid carcinoma $(n=24)$; Group 2, non-conventional papillary thyroid carcinoma $(n=5)$ including follicular variant of papillary thyroid carcinoma $(n=2)$, follicular thyroid carcinoma $(n=2)$, and medullary thyroid carcinoma $(n=1)$; $E_{M e a n}$, mean elasticity; $E_{M a x}$ maximum elasticity; $E_{S D}$, one standard deviation of elastographic values; $\mathrm{kPa}$, kilo-Pascal 


\section{Discussion}

SWE is operator independent in terms of adding stress but is operator dependent in the placement of ROI, and the difficulty in images and the subjective features of selecting representative location of ROI have been reported as the causes of variability of SWE [14, 27, 28].

In this study, we examined a new method of placement of ROI by tracing the total nodule and evaluated the reproducibility as well as compared total nodular ROI with conventional focal ROI using a 3-mm circular area. The intrarater CVs of the total nodular ROI method in rater 1 and rater 2 were significantly lower than those of the focal nodular ROI method in rater 1 $(1.7 \%$ vs. $13.4 \%, p<0.001)$ and in rater $2(1.4 \%$ vs. $16.9 \%$, $p<0.001)$ within the image and in rater $1(7.6 \% \mathrm{vs}$. $12.3 \%, p=0.040)$ and in rater $2(7.5 \%$ vs. $19.8 \%, p=$ $0.004)$ in different images. Moreover, the interrater CV of the total nodular ROI method was significantly lower than that of the focal nodular ROI method $(14.9 \%$ vs. $19.0 \%, p=0.030$ ). Bardet et al. [26] reported that the intra- and interobserver CVs for the mean EI in the focal nodular ROI were 23 and 26\%, respectively. Brezak et al. [38] reported that the intra- and interreader CVs in the focal nodular ROI for the mean EI were 13 and 21\%, respectively. Our results are compatible with those reported by these two previous studies.

Moreover, the agreement of the mean EI between the total and focal nodular area ROI was evaluated by ICC in this study. The mean EI in the total nodular ROI showed better agreement than in the focal nodular ROI in intra-assay agreement (ICC, 0.959 vs. 0.894 in rater 1 and 0.976 vs. 0.734 in rater 2) and also in interrater agreement (ICC, 0.863 vs. 0.783). Bland-Altman plot analysis of interrater agreement showed better interrater agreement of EI in the total nodular ROI than in the focal nodular ROI. Moreover, our study revealed that SWE EI measurement in the total nodular ROI was more reproducible and showed less variability compared to the mean EI in the focal nodular ROI and suggested that it may be a valuable and standardized method in clinical practice.

A comparison of the EI with the degree of fibrosis, $E_{\text {Mean }}$ and $E_{\text {Max }}$ showed a correlation with the percent of fibrosis. Additionally, comparison of EI with surgical histopathology revealed that high EI areas in SWE in thyroid cancer were concordant to the areas of fibrosis. PTC is commonly associated with fibrotic change particularly evident at the advancing edge [34] and up to $80 \%$ of PTC show fibrotic change with various degrees $[39,40]$, while stromal component of follicular neoplasm especially adenoma is typically scant [34] and occasionally shows stromal fibrosis and hemorrhage [40]. Regarding follicular thyroid carcinoma, several studies reported that SWE did not show significantly elevated elasticity
[7, 20] similar to benign nodules. Rago et al. [30] reported that the elasticity of the thyroid nodules with stain elastography did not correlate with cell number, and nodule stiffness was correlated with the degree of fibrosis, which was more evident in classic PTC than in follicular variant PTC. Yi et al. [31] reported that the strain ratio of US elastography was positively correlated with the degree of fibrosis of PTC on surgical histopathology. Fukuhara et al. [32, 33] reported that when malignant thyroid nodules were classified according to the degree of fibrosis on histopathology, SWE showed high shear wave velocity in nodules with severe fibrosis and malignant nodules with no fibrosis showing similar shear wave velocity with benign nodules with no fibrosis, and the effect of cell density on shear wave velocity was insignificant. These reports suggest that fibrosis plays a major role in the elasticity of the thyroid nodules, and elevated elasticity in thyroid cancer is mainly related with fibrosis, which is frequent in PTC and nonconventional PTC with less or no fibrosis showing insignificant or slight elevation of elasticity including follicular carcinoma and follicular variant PTC [25, 26]. Although $\mathrm{E}_{\mathrm{Mean}}$ has been reported to be significantly higher in conventional PTC than in non-conventional PTC, non-conventional PTC in our study was a heterogeneous group of thyroid cancers and the number was too small. Thus, large prospective studies evaluating non-conventional PTC are needed to verify our results.

Our data revealed that the percentage of high EI (greater than $36 \mathrm{kPa}$ ) area of the nodule showed a correlation with the degree of fibrosis (percentage of fibrosis on surgical histopathology). Moreover, EI ( $\mathrm{E}_{\mathrm{Max}}$ and $\left.\mathrm{E}_{\mathrm{Mean}}\right)$ was correlated with the degree of fibrosis. Additionally, the location of fibrosis was concordant with high EI area. Hence, the degree and location of fibrosis on histopathology were closely correlated with the high EI of the thyroid nodule. Diverse elasticity in PTC may reflect various degrees of fibrosis in PTC, resulting in the discrepant cut-off values in the diagnosis of malignant thyroid nodules, because more than $80 \%$ of malignant nodules are composed of PTC. A wide range of cut-off values of EI in detecting malignancy from $34 \mathrm{kPa}$ to $90 \mathrm{kPa}$ has been reported [9,16-25], and which may be due to the various degrees of fibrosis in different patients and different types of tumors in the same study and also in the different study groups.

\section{Conclusions}

Our study revealed that the mean EI in the total nodular ROI showed higher reproducibility and better agreement in intra- and interrater assay than in the focal nodular ROI when evaluating the ICC, CV, and Bland-Altman analysis, which may be due to the multiple reasons including the avoidance of the subjective variance of 
placement of ROI in the focal nodular area. We suggest that the total nodular ROI method may be a valuable and standardized method in clinical practice. Our results showed that fibrosis increased SWE elasticity in the histopathology of the thyroid nodule, which might lead to the discrepancy of the cut-off values in detecting thyroid cancer. A limitation of this study is the relatively small number of patients, and future studies with larger sample sizes may be needed for further clarification of the possible characteristic features of SWE.

\section{Abbreviations}

CNB: Core-needle biopsy; CV: Coefficient of variation; El: Elasticity index; $E_{\text {Max: }}$ Maximum elasticity; $E_{\text {Mean: }}$ Mean elasticity; $E_{M i n}$ : Minimum elasticity; $E_{S D}$ : One standard deviation of elastographic values; FNA: Fine-needle aspiration cytology; ICC: Intraclass correlation coefficient; PTC: Papillary thyroid carcinoma; ROI: Region of interest; SWE: Shear wave elastography; US: Ultrasound

\section{Acknowledgments}

We would like to thank the research coordinator Maeja Kim from the Soonchunhyang University Hospital for her help in data collection.

\section{Authors' contributions}

MHY analyzed and interpreted study concepts. MHY, HJK and SYP analyzed and interpreted study design. HJK and IHC obtained the data. SJK, HKP and DWB controlled the quality of data and algorithms. HJK and SYP conducted the statistical analysis. MHY and HJK prepared and edited for the manuscript. IHC, SJK, HKP, DWB and KS reviewed the manuscript for critical revisions. All authors have read and approved the manuscript.

\section{Funding}

This work was supported by the Soonchunhyang University Research Fund. None of the funding sources were involved in the design of the study, data collection and analysis, interpretation of results, writing of the manuscript, or in the decision to submit the manuscript for publication.

\section{Availability of data and materials}

The datasets used and analyzed in the current study are available from the corresponding author on reasonable request.

\section{Ethics approval and consent to participate}

The Institutional Review Board of Soonchunhyang University Hospital approved the study (approval no. 2018-11-019). The requirement for informed consent for this study was waived by the institutional review board because researchers only accessed the database for analysis purposes and personal identifying information was not accessed.

\section{Consent for publication}

Not applicable.

\section{Competing interests}

The authors declare that they have no competing interests.

\section{Author details}

${ }^{1}$ Division of Endocrinology and Metabolism, Department of Internal Medicine, Soonchunhyang University Hospital, Soonchunhyang University College of Medicine, 59 Daesagwan-ro, Yongsan-gu, Seoul 140-743, Republic of Korea. ${ }^{2}$ Elim Thyroid Clinic, Seoul, South Korea. ${ }^{3}$ Department of Pathology, Soonchunhyang University Hospital, Soonchunhyang University College of Medicine, Seoul, South Korea. ${ }^{4}$ Department of Biostatistics, Soonchunhyang University Hospital, Soonchunhyang University College of Medicine, Seoul, South Korea. ${ }^{5}$ Division of Endocrinology and Metabolism, Department of Internal Medicine, Soonchunhyang University Cheonan Hospital, Soonchunhyang University College of Medicine, Cheonan, South Korea.
Received: 13 June 2019 Accepted: 5 December 2019

Published online: 12 February 2020

\section{References}

1. Bongiovanni M, Spitale A, Faquin WC, Mazzucchelli L, Baloch ZW. The Bethesda system for reporting thyroid cytopathology: a meta-analysis. Acta Cytol. 2012;56(4):333-9.

2. Mazzaferri EL. Management of a solitary thyroid nodule. N Engl J Med. 1993; 328(8):553-9.

3. Cibas ES, Ali SZ. The 2017 Bethesda system for reporting thyroid cytopathology. Thyroid. 2017;27(11):1341-6.

4. Alexander EK. Approach to the patient with a cytologically indeterminate thyroid nodule. J Clin Endocrinol Metab. 2008;93(11):4175-82.

5. Rago T, Santini F, Scutari M, Pinchera A, Vitti P. Elastography: new developments in ultrasound for predicting malignancy in thyroid nodules. J Clin Endocrinol Metab. 2007;92(8):2917-22.

6. Ragazzoni F, Deandrea M, Mormile A, Ramunni MJ, Garino F, Magliona G, Motta M, Torchio B, Garberoglio R, Limone P. High diagnostic accuracy and interobserver reliability of real-time elastography in the evaluation of thyroid nodules. Ultrasound Med Biol. 2012;38(7):1154-62.

7. Asteria C, Giovanardi A, Pizzocaro A, Cozzaglio L, Morabito A, Somalvico F, Zoppo A. US-elastography in the differential diagnosis of benign and malignant thyroid nodules. Thyroid. 2008;18(5):523-31.

8. Azizi G, Keller J, Lewis M, Puett D, Rivenbark K, Malchoff C. Performance of elastography for the evaluation of thyroid nodules: a prospective study. Thyroid. 2013;23(6):734-40.

9. Sebag F, Vaillant-Lombard J, Berbis J, Griset V, Henry JF, Petit P, Oliver C. Shear wave elastography: a new ultrasound imaging mode for the differential diagnosis of benign and malignant thyroid nodules. J Clin Endocrinol Metab. 2010;95(12):5281-8.

10. Gennisson JL, Deffieux T, Fink M, Tanter M. Ultrasound elastography: principles and techniques. Diagn Interv Imaging. 2013:94(5):487-95.

11. Kamaya A, Machtaler S, Safari Sanjani S, Nikoozadeh A, Graham Sommer F, Pierre Khuri-Yakub BT, Willmann JK, Desser TS. New technologies in clinical ultrasound. Semin Roentgenol. 2013;48(3):214-23.

12. Garra BS. Imaging and estimation of tissue elasticity by ultrasound. Ultrasound Q. 2007:23(4):255-68.

13. Athanasiou A, Tardivon A, Tanter M, Sigal-Zafrani B, Bercoff J, Deffieux T, Gennisson JL, Fink M, Neuenschwander S. Breast lesions: quantitative elastography with supersonic shear imaging--preliminary results. Radiology. 2010:256(1):297-303.

14. Sigrist RMS, Liau J, Kaffas AE, Chammas MC, Willmann JK. Ultrasound Elastography: review of techniques and clinical applications. Theranostics. 2017;7(5):1303-29.

15. Garra BS. Elastography: history, principles, and technique comparison. Abdom Imaging. 2015;40(4):680-97.

16. Wang F, Chang C, Chen M, Gao Y, Chen YL, Zhou SC, Li JW, Zhi WX. Does lesion size affect the value of shear wave Elastography for differentiating between benign and malignant thyroid nodules? J Ultrasound Med. 2018; 37(3):601-9.

17. Azizi G, Keller JM, Mayo ML, Piper K, Puett D, Earp KM, Malchoff CD. Shear wave elastography and Afirma gene expression classifier in thyroid nodules with indeterminate cytology: a comparison study. Endocrine. 2018;59(3): 573-84.

18. Duan SB, Yu J, Li X, Han ZY, Zhai HY, Liang P. Diagnostic value of twodimensional shear wave elastography in papillary thyroid microcarcinoma. OncoTargets Ther. 2016;9:1311-7.

19. Gregory A, Bayat M, Kumar V, Denis M, Kim BH, Webb J, Meixner DD, Ryder $M$, Knudsen JM, Chen S, et al. Differentiation of benign and malignant thyroid nodules by using comb-push ultrasound shear Elastography: a preliminary two-plane view study. Acad Radiol. 2018;25(11):1388-97.

20. Veyrieres JB, Albarel F, Lombard JV, Berbis J, Sebag F, Oliver C, Petit P. A threshold value in shear wave elastography to rule out malignant thyroid nodules: a reality? Eur J Radiol. 2012;81(12):3965-72.

21. Kim H, Kim JA, Son EJ, Youk JH. Quantitative assessment of shear-wave ultrasound elastography in thyroid nodules: diagnostic performance for predicting malignancy. Eur Radiol. 2013;23(9):2532-7.

22. Park AY, Son EJ, Han K, Youk JH, Kim JA, Park CS. Shear wave elastography of thyroid nodules for the prediction of malignancy in a large scale study. Eur J Radiol. 2015;84(3):407-12. 
23. Liu Z, Jing H, Han X, Shao H, Sun YX, Wang QC, Cheng W. Shear wave elastography combined with the thyroid imaging reporting and data system for malignancy risk stratification in thyroid nodules. Oncotarget. 2017;8(26):43406-16.

24. Chang N, Zhang $X$, Wan W, Zhang C, Zhang $X$. The preciseness in diagnosing thyroid malignant nodules using shear-wave Elastography. Med Sci Monit. 2018;24:671-7.

25. Bhatia KS, Tong CS, Cho CC, Yuen EH, Lee YY, Ahuja AT. Shear wave elastography of thyroid nodules in routine clinical practice: preliminary observations and utility for detecting malignancy. Eur Radiol. 2012;22(11): 2397-406.

26. Bardet S, Ciappuccini R, Pellot-Barakat C, Monpeyssen H, Michels JJ, Tissier F, Blanchard D, Menegaux F, de Raucourt D, Lefort M, et al. Shear wave Elastography in thyroid nodules with indeterminate cytology: results of a prospective Bicentric study. Thyroid. 2017;27(11):1441-9.

27. Swan KZ, Nielsen VE, Bibby BM, Bonnema SJ. Is the reproducibility of shear wave elastography of thyroid nodules high enough for clinical use? A methodological study. Clin Endocrinol. 2017;86(4):606-13.

28. Anvari A, Dhyani M, Stephen AE, Samir AE. Reliability of shear-wave Elastography estimates of the young Modulus of tissue in follicular thyroid neoplasms. AJR Am J Roentgenol. 2016;206(3):609-16.

29. Hedrick W. Technology for diagnostic sonography. St Louis: Elsevier Mosby; 2013.

30. Rago T, Scutari M, Loiacono V, Santini F, Tonacchera M, Torregrossa L, Giannini R, Borrelli N, Proietti A, Basolo F, et al. Low elasticity of thyroid nodules on ultrasound Elastography is correlated with malignancy, degree of fibrosis, and high expression of Galectin-3 and Fibronectin-1. Thyroid. 2017;27(1):103-10.

31. Yi L, Qiong W, Yan W, Youben F, Bing H. Correlation between ultrasound Elastography and histologic characteristics of papillary thyroid carcinoma. Sci Rep. 2017;7:45042.

32. Fukuhara T, Matsuda E, Endo Y, Takenobu M, Izawa S, Fujiwara K, Kitano H Correlation between quantitative shear wave elastography and pathologic structures of thyroid lesions. Ultrasound Med Biol. 2015;41(9):2326-32.

33. Fukuhara T, Matsuda E, Endo Y, Donishi R, Izawa S, Fujiwara K, Kitano H, Takeuchi H. Impact of fibrotic tissue on shear wave velocity in thyroid: an ex vivo study with fresh thyroid specimens. Biomed Res Int. 2015;2015: 569367

34. Lloyd RV, Osamura RY, Kloppel G, Rosai J. WHO classification of Tumours of endocrine organs. 4th ed. Lyon: IARC Press; 2017.

35. Bland JM, Altman DG. A note on the use of the intraclass correlation coefficient in the evaluation of agreement between two methods of measurement. Comput Biol Med. 1990;20(5):337-40.

36. Kottner J, Audige L, Brorson S, Donner A, Gajewski BJ, Hrobjartsson A, Roberts C, Shoukri M, Streiner DL. Guidelines for reporting reliability and agreement studies (GRRAS) were proposed. J Clin Epidemiol. 2011;64(1):96-106.

37. Bland JM, Altman DG. Statistical methods for assessing agreement between two methods of clinical measurement. Lancet (London, England). 1986; 1(8476):307-10.

38. Brezak R, Hippe D, Thiel J, Dighe MK. Variability in stiffness assessment in a thyroid nodule using shear wave imaging. Ultrasound Q. 2015;31(4):243-9.

39. Koperek O, Asari R, Niederle B, Kaserer K. Desmoplastic stromal reaction in papillary thyroid microcarcinoma. Histopathology. 2011;58(6):919-24.

40. Kumar V, Abbas AK, Aster JC. Robbins and Cotran pathologic basis of disease. 9th ed. Philadelphia; 2015. https://www.elsevier.com/books/robbinsand-cotran-pathologic-basis-of-disease/kumar/978-1-4557-2613-4.

\section{Publisher's Note}

Springer Nature remains neutral with regard to jurisdictional claims in published maps and institutional affiliations.

Ready to submit your research? Choose BMC and benefit from:

- fast, convenient online submission

- thorough peer review by experienced researchers in your field

- rapid publication on acceptance

- support for research data, including large and complex data types

- gold Open Access which fosters wider collaboration and increased citations

- maximum visibility for your research: over $100 \mathrm{M}$ website views per year

At BMC, research is always in progress.

Learn more biomedcentral.com/submissions 